\title{
Influence of Ultraviolet Irradiation on Spores of Obligate Anaerobes Causing Flat Sour Spoilage of Canned Drinks
}

\author{
(A New Type of Flat Sour Spoilage. IV)
}

(Received April 24, 1981)

\author{
Akihiko NAKaYama and Rieko SHINYA \\ (Toyo Institute of Food Technology: 2-23-4 Minami Hanayashiki, Kawanishi City, Hyogo)
}

\begin{abstract}
The ultraviolet (UV) resistance of the spores of six strains causing O. A. flat sour spoilage was estimated, and the effects of UV irradiation on the heat resistance of the spores were also studied.

The UV doses required to reduce the number of survivors to one-tenth of the original number ranged from 1300 to $2600 \mathrm{ergs} / \mathrm{mm}^{2}$, which is not especially high, in contrast to the high heat resistance. The effects of UV irradiation on the heat resistance of the spores tested differed among the different strains. However, in the range of the UV doses used, UV irradiation decreased the heat resistance at least to one-half.

Therefore, prior UV irradiation of dissolved sugar, which is most strongly suspected as a source of the spores, can be employed as a countermeasure to prevent O. A. flat sour spoilage of canned drinks kept hot in vending machines.
\end{abstract}

Key words: UV resistance of spores; UV effects on heat resistance of spores; thermophilic obligate anaerobes; flat sour spoilage; canned drinks; hot vending

\section{Introduction}

Previous papers ${ }^{1) \sim 4}$ ) have described a new type of flat sour spoilage (O. A. flat sour spoilage) in commercial canned coffee and shiruko which were kept hot in vending machines, and it was reported that the heat resistance of the causative bacteria is so high that the conventional heating process is insufficient to sterilize the canned drinks. Sugar, which is the only common ingredient used in both canned coffee and shiruko, is most strongly suspected as a source of the causative bacteria ${ }^{4)}$.

Therefore, one possible approach to prevent O. A. flat sour spoilage is previous sterilization of the sugar by some means other than thermal processes. For this purpose, ultraviolet (UV) irradiation seems to be the only convenient and effective method. In this paper, the UV resistance and the effects of UV irradiation on the heat resistance of the spores are reported.

\section{Materials and Methods}

\section{Microorganisms}

The bacteria tested were the six isolates (strain Nos. 24-1, 13-1, 26-11, 27-8, 28-3 and 28-4) obtained as the causative bacteria of O. A. flat sour spoilage. Strain Nos. 24-1 and 13-1 were isolated from spoiled canned coffee samples from manufacturers $B$ and $F$, respectively ${ }^{2)}$. Strain Nos. 26-11 and 27-8 were isolated from spoiled canned coffee samples from manufacturer $\mathrm{J}^{3)}$. Strain Nos. 28-3 and 28-4 were isolated from spoiled canned shiruko samples from manufacturer $\mathrm{K}^{4}$. The principal characteristics of the strains are shown in Table 1.

Bacillus subtilis 3610 (ATCC 6051) was used as a standard in comparing the UV resistance and heat resistance of these strains. The strain was obtained from Prof. Hajime Kadota, Faculty of Agriculture, Kyoto University. 


\section{Preparation of Spore Suspensions}

Spore suspensions were prepared by the method described in the previous paper ${ }^{2)}$ except for Bacillus subtilis.

Bacillus subtilis was grown at $35^{\circ} \mathrm{C}$ on the standard method agar (SMA) ${ }^{5}$. Spores were harvested after 4 days of incubation and suspended in sterile deionized water of the same volume as the medium. The suspension was washed and treated by the method described previously ${ }^{2)}$ without heat treatment.

\section{$U V$ Irradiation}

The UV-light source used was a germicidal lamp (Hitachi GL-15, $15 \mathrm{~W}$ ) emitting predominantly $2537 \AA$ radiation. Dose rates were measured with a Topcon UVR-254 UV radiometer (Tokyo Kogaku Kikai Co. Ltd.).

Aliquots (2 $\mathrm{ml}$ each) of the spore suspensions were irradiated in a $9.5 \mathrm{~cm}$ Petri dish at a dose rate of 400 or $500 \mu \mathrm{w} / \mathrm{cm}^{2}$. During UV irradiation, the Petri dish was rotated slowly to ensure uniform irradiation.

\section{Heating}

The spores of the strains causing O. A. flat sour spoilage irradiated as described above were heated at $120 \pm 0.1^{\circ} \mathrm{C}$ by the method described previously ${ }^{2}$.

The spores of Bacillus subtilis were heated at 90,95 and $100^{\circ} \mathrm{C}$ by the method described previously ${ }^{2)}$.

\section{Determination of Survivors}

The six strains causing O. A. flat sour spoilage were irradiated and heated for desired periods, then the numbers of survivors were determined by the MPN method with $\mathrm{mTGC}^{6)}$; in the case of Bacillus subtilis the numbers of survivors were determined by the pour-plate method with SMA. The mTGC was incubated at $55^{\circ} \mathrm{C}$ for 10 days and the SMA was incubated at $35^{\circ} \mathrm{C}$ for 10 days.

\section{Results and Discussion}

\section{UV Resistance}

UV survival curves of the 6 strains causing O. A. flat sour spoilage are shown in Fig. 1. From these UV survival curves, the $D_{\mathrm{UV}}$ values, which are defined as the UV doses required to reduce the numbers of survivors to one-tenth of the original populations, were determined. The $D_{\mathrm{uv}}$ values ranged from
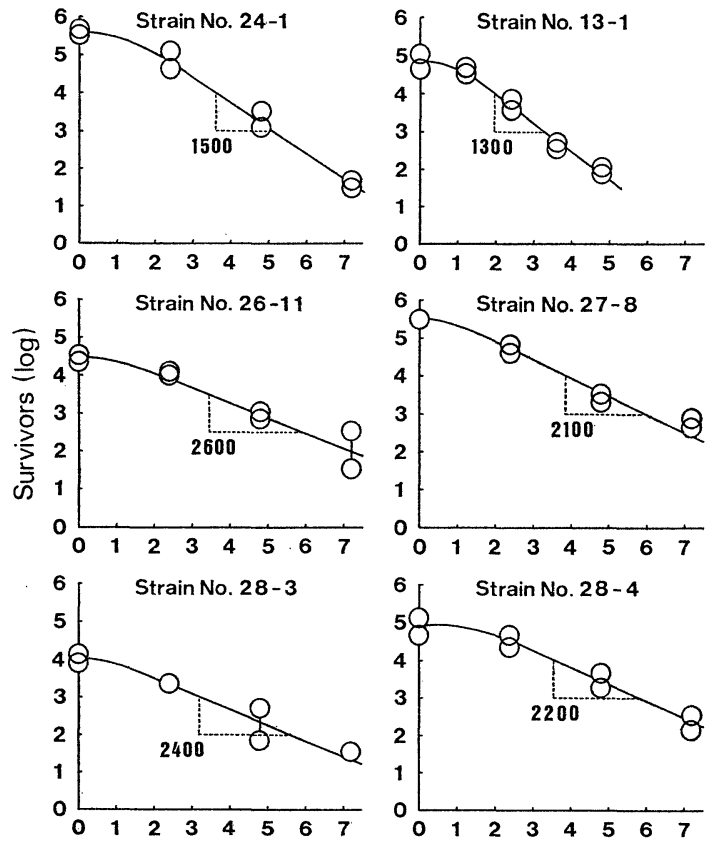

UV DOSE (ergs $/ \mathrm{mm}^{2} \times 10^{-3}$ )

Fig. 1. UV survival curves for spores of the six strains causing $\mathrm{O}$. A. flat sour spoilage Numerals are $D_{\mathrm{UV}}$ values.

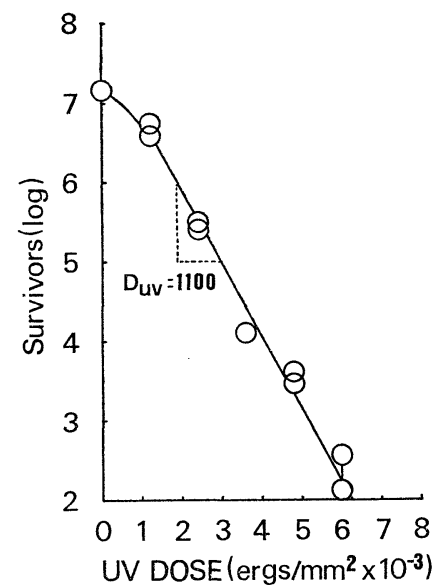

Fig. 2. UV survival curve for spores of Bacil. lus subtilis

1300 to $2600 \mathrm{ergs} / \mathrm{mm}^{2}$. These values are not especially high as compared to the known values for other spores ${ }^{7}$ and the value for the spores of Bacillus subtilis $\left(1100 \mathrm{ergs} / \mathrm{mm}^{2}\right)$ obtained by the same method (Fig. 2). However, the heat resistance of the spores of Bacillus subtilis was very low. The $D$ values at 100,95 and $90^{\circ} \mathrm{C}\left(D_{100}, D_{95}\right.$ and $\left.D_{90}\right)$ were 


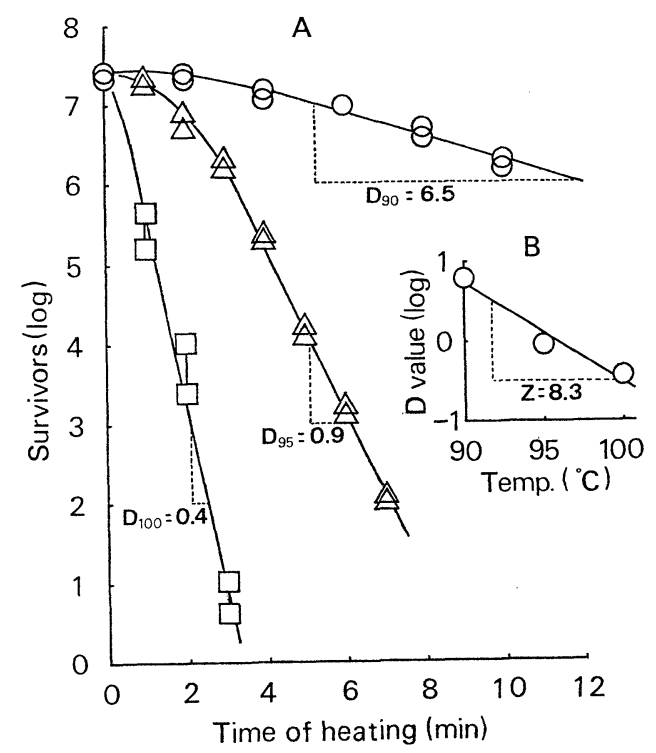

Fig. 3. Heat-survival curves and thermal destruction curve for spores of Bacillus subtilis

A. Heat-survival curves: -O-, heated at $90^{\circ} \mathrm{C} ;-\triangle-$, heated at $95^{\circ} \mathrm{C} ;-\square-$, heated at $100^{\circ} \mathrm{C}$

B. Thermal destruction curve
$0.4,0.9$ and 6.5 , respectively, as shown in Fig. 3. It is considered that, estimating from the $z$-value $\left(8.3^{\circ} \mathrm{C}\right)$, these values were $1 / 8600 \sim$ $1 / 71000$ of those of the spores of the six strains.

The $D$ values at $120^{\circ} \mathrm{C}\left(D_{120}\right)$ reported previously $^{2) ~ 4)}$ and the $D_{\mathrm{UV}}$ values for the spores of the strains are summarized in Table 2 . The $D_{120}$ value for the spores of strain No. 28-3 was 8. 2 times larger than that for the spores of strain No. 13-1. However, strain No. 28-3 showed a $D_{\mathrm{Uv}}$ value 1.8 times that of strain No. 13-1. Moreover, the $D_{120}$ value for the spores of strain No. 28-3 was about 40000 times that for the spores of Bacillus subtilis as estimated from the $z$-value. However, strain No. 28-3 showed a $D_{\text {Uv }}$ value only 2.2 times greater than that of Bacillus subtilis.

These results indicate that there is no relation between the UV resistance and the heat resistance of these spores, and that, unlike the heat resistance, the UV resistance of these 6 strains is not especially high.

Effects of UV Irradiation on Heat Resistance Heat survival curves for the spores irradi-

Table 1. Characteristics of the Strains

\begin{tabular}{|c|c|c|c|c|c|c|}
\hline Strain No. & $24-1$ & $13-1$ & $26-11$ & $27-8$ & $28-3$ & $28-4$ \\
\hline Origin & \multicolumn{2}{|c|}{ Canned coffee } & \multicolumn{2}{|c|}{ Canned coffee } & \multicolumn{2}{|c|}{ Canned shiruko } \\
\hline (manufacturer) & (B) & $(\mathrm{F})$ & $(\mathrm{J})$ & $(\mathrm{J})$ & $(\mathrm{K})$ & $(\mathrm{K})$ \\
\hline $\begin{array}{l}\text { Heat resistance } \\
\left(D_{120}\right)\end{array}$ & 25 & 5.6 & 23 & 25 & 46 & 22 \\
\hline Gram stain & - & - & - & - & - & - \\
\hline Acid from & & & & & & \\
\hline glucose & + & + & + & + & + & + \\
\hline lactose & - & - & - & - & - & - \\
\hline salicin & - & - & - & - & - & - \\
\hline sucrose & - & - & - & - & - & - \\
\hline Production of & & & & & & \\
\hline indole & - & - & - & - & - & - \\
\hline $\mathrm{H}_{2} \mathrm{~S}$ & + & + & + & + & + & + \\
\hline Coagulation of milk & - & - & - & - & - & - \\
\hline Digestion of & & & & & & \\
\hline albumin & - & - & - & - & - & - \\
\hline meat & - & - & - & - & - & - \\
\hline Nitrite from nitrate & - & - & + & - & + & - \\
\hline Hydrolysis of gelatin & - & + & - & - & - & - \\
\hline
\end{tabular}


Table 2. Heat Resistance and UV Resistance

\begin{tabular}{c|cc} 
Strain No. & $\begin{array}{c}\text { Heat resistance } \\
D_{120} \text { value }\end{array}$ & $\begin{array}{c}\text { UV resistance } \\
D_{\mathbf{U} \text { V value*1 }}\end{array}$ \\
\hline $24-1$ & 25 & 1500 \\
$13-1$ & 5.6 & 1300 \\
$26-11$ & 23 & 2600 \\
$27-8$ & 25 & 2100 \\
$28-3$ & 46 & 2400 \\
$28-4$ & 22 & 2200 \\
Bacillus subtilis & $0.4^{* 2}$ & 1100
\end{tabular}

*1 UV dose required to reduce the number of the survivors to one-tenth of the original popula. tion

*2 $D$ value at $100^{\circ} \mathrm{C}$

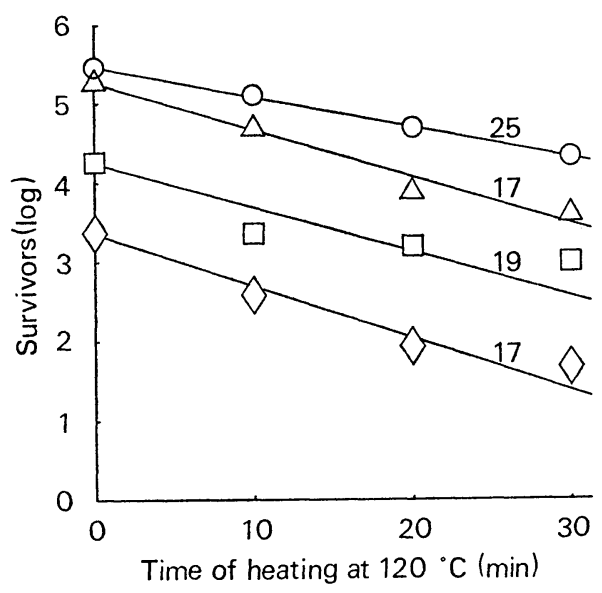

Fig. 4. Effects of UV irradiation on the heat resistance of strain No. 24-1

Spore suspensions were irradiated at 500 $\mu \mathrm{w} / \mathrm{cm}^{2}$ for $0 \mathrm{sec}$ (control, - - -), for $30 \mathrm{sec}$ $(-\triangle-)$, for $60 \mathrm{sec}$ (一 $\square)$, and for $90 \mathrm{sec}$ $(-\diamond-)$, and subjected to heat treatment at $120^{\circ} \mathrm{C}$.

Numerals on the plots are $D_{120}$ values.

ated at the dose rate of $500 \mu \mathrm{w} / \mathrm{cm}^{2}$ for 30 , 60 and $90 \mathrm{sec}$ are shown in Figs. 4, 5, 6, 7, 8 and 9. In the figures, each symbol is the mean value of the data obtained in duplicate experiments. The differences between the $D_{120}$ values for the spores of some strains and those for the spores of the same strains given in the previous paper ${ }^{2) \sim 4}$ and in Tables 1 and 2 are due to the fact that spores of different batches were used.

The $D_{120}$ value for the spores of strain No. 24-1 was 25 , and the $D_{120}$ values for the spores irradiated for 30,60 and $90 \mathrm{sec}$ were 17,19

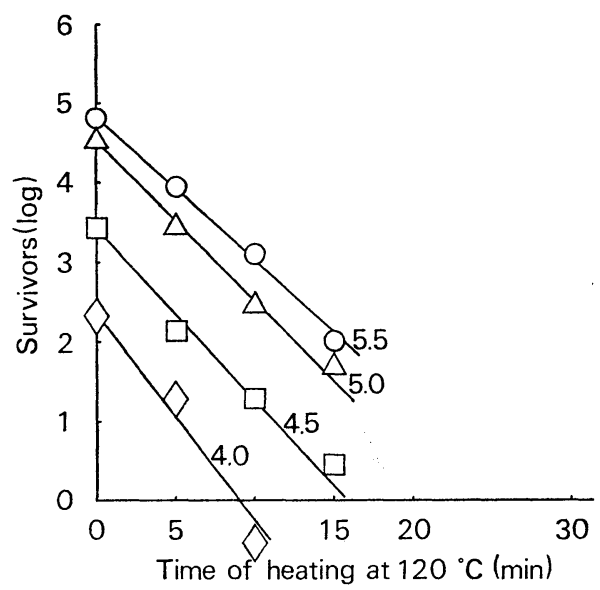

Fig. 5. Effects of UV irradiation on the heat resistance of strain No. 13-1

Spore suspensions were irradiated at 500 $\mu \mathrm{w} / \mathrm{cm}^{2}$ for $0 \mathrm{sec}$ (control, - - ), for $30 \mathrm{sec}$ $(-\Delta-)$, for $60 \mathrm{sec}(-\square-)$, and for $90 \mathrm{sec}$ $(-\diamond-)$, and subjected to heat treatment at $120^{\circ} \mathrm{C}$.

Numerals on the plots are $D_{120}$ values.

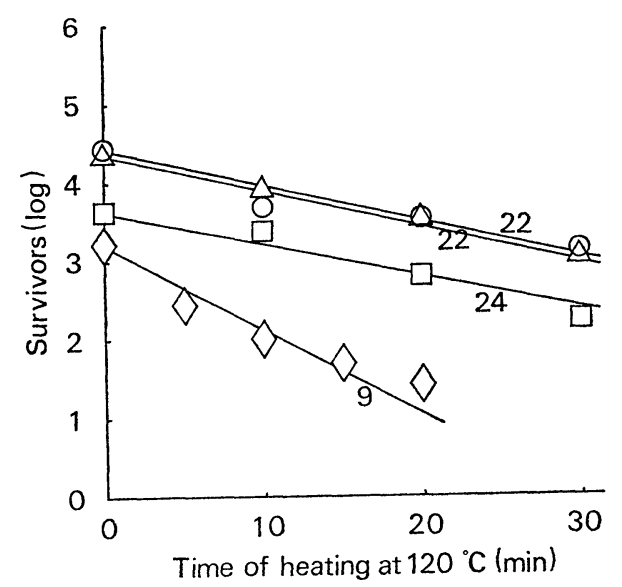

Fig. 6. Effects of UV irradiation on the heat resistance of strain No. 26-11

Spore suspensions were irradiated at 500 $\mu \mathrm{w} / \mathrm{cm}^{2}$ for $0 \mathrm{sec}$ (control, -O-), for $30 \mathrm{sec}$ $(-\Delta-)$, for $60 \mathrm{sec}$ ( $-\square-)$, and for $90 \mathrm{sec}$ $(-\diamond-)$, and subjected to heat treatment at $120^{\circ} \mathrm{C}$.

Numerals on the plots are $D_{120}$ values.

and 17, respectively (Fig. 4). The results suggest that, in the range of UV dose used, the $D_{120}$ values were decreased to $70 \%$ of the original levels by the UV irradiation. However, no significant changes were observed with change of the UV dose. 


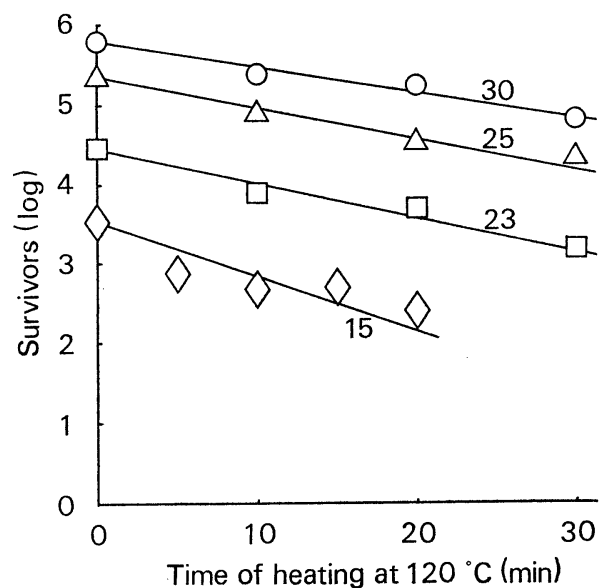

Fig. 7. Effects of UV irradiation on the heat resistance of strain No. 27-8

Spore suspensions were irradiated at 500 $\mu \mathrm{w} / \mathrm{cm}^{2}$ for $0 \mathrm{sec}$ (control, - - -), for $30 \mathrm{sec}$ $(-\Delta-)$, for $60 \mathrm{sec}$ (- $\square-)$, and for $90 \mathrm{sec}$ $(-\diamond-)$, and subjected to heat treatment at $120^{\circ} \mathrm{C}$.

Numerals on the plots are $D_{120}$ values.

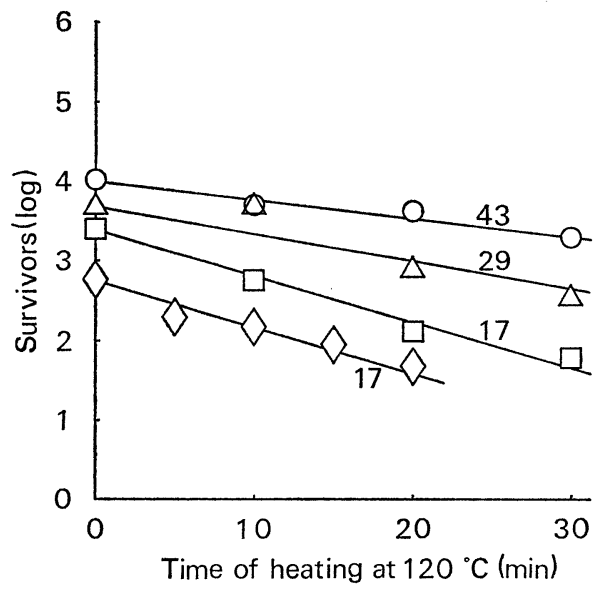

Fig. 8. Effects of UV irradiation on the heat resistance of strain No. 28.3

Spore suspensions were irradiated at 500 $\mu \mathrm{w} / \mathrm{cm}^{2}$ for $0 \mathrm{sec}$ (control, - - -), for $30 \mathrm{sec}$ $(-\Delta-)$, for $60 \mathrm{sec}(-\square-)$, and for $90 \mathrm{sec}$ $(-\diamond-)$, and subjected to heat treatment at $120^{\circ} \mathrm{C}$.

Numerals on the plots are $D_{120}$ values.

The $D_{120}$ value for the spores of strain No. 13-1 was 5.5, and decreased to 5.0, 4.5 and 4. 0 with increase of the UV dose (Fig. 5).

The $D_{120}$ value for the spores of strain No. 26-11 was 22, and after UV irradiation at

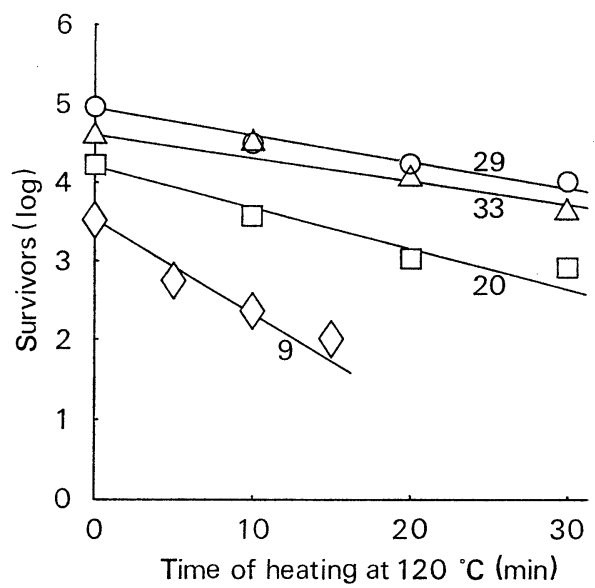

Fig. 9. Effects of UV irradiation on the heat resistance of strain No. 28.4

Spore suspensions were irradiated at 500 $\mu \mathrm{w} / \mathrm{cm}^{2}$ for $0 \mathrm{sec}$ (control, - $\mathrm{O}-$ ), for $30 \mathrm{sec}$ $(-\triangle-)$, for $60 \mathrm{sec}$ (- $\square-)$, and for $90 \mathrm{sec}$ $(-\diamond-)$, and subjected to heat treatment at $120^{\circ} \mathrm{C}$.

Numerals on the plots are $D_{120}$ values.

$500 \mu \mathrm{w} / \mathrm{cm}^{2}$ for $30 \mathrm{sec}$ no significant decrease in the number of the spores or in the $D_{120}$ value was observed. Even after $60 \mathrm{sec}$ of UV irradiation, the $D_{120}$ value was not changed, but after $90 \mathrm{sec}$ it decreased to one-half (Fig. 6).

The $D_{120}$ value for the spores of strain No. $27-8$ was 30 , and decreased to 25,23 and 15 with increase of the UV dose (Fig.7).

The $D_{120}$ value for the spores of strain No. $28-3$ was 43 , and decreased to 29,17 and 17 with increase of the UV dose (Fig. 8).

The $D_{120}$ value for the spores of strain No. 28-4 was unchanged after UV irradiation for $30 \mathrm{sec}$, and after UV irradiation for 60 and $90 \mathrm{sec}$, the values decreased to two-thirds and one-third, respectively (Fig. 9).

Judging from these results, in the range of UV doses used, the six strains can be divided into three types as regards the effects of UV irradiation on the heat resistance.

In the first type, strain No.24-1, UV irradiation decreases the heat resistance, but an increase of the UV dose does not cause any further significant change in the heat resistance.

In the second type, strain Nos. 13-1, 27-8 and $28-3$, the heat resistance decreases with 
increase of the UV dose.

In the third type, strain Nos. $26-11$ and 28 4 , the heat resistance is not changed by a limited UV dose, but is greatly decreased by a larger dose.

From these results on the UV resistance and the effects of UV irradiation on the heat resistance, it is concluded that the spores of the six strains causing $O$. A. flat sour spoilage do not have an especially high resistance to UV light, in contrast to their heat resistance, and at least a half of the original heat resistance is lost upon UV irradiation.

It is suggested that prior UV irradiation of the dissolved sugar can be employed as a countermeasure to prevent $O$. A. flat sour spoilage of canned drinks which are often kept hot in vending machines in Japan.

\section{Acknowledgement}

The authors wish to express their thanks to Prof. Hajime Kadota, Faculty of Agriculture, Kyoto University, for many helpful discussions and suggestions throughout this study. Thanks are also due to Prof. Shigeru Otsuka, Toyo Junior College of Food Technology, for many discussions, and to Miss
Junko Sonobe, Toyo Institute of Food Technology, for her technical assistance.

This study was supported in part by a scientific research grant from the Ministry of Health and Welfare.

A part of this paper was presented at the annual meeting of the Japan. Soc. Sci. Fish. on Oct. 5, 1979, in Hakodate.

\section{References}

1) Nakayama, A., Samo, S., Ikegami, Y.: Bull. Japan. Soc. Sci. Fish., 43, 899 (1977).

2) Nakayama, A., Samo, S.: ibid., 46, 1117 1123 (1980).

3) Nakayama, A., Shinya, R.: J. Food Hyg. Soc. Japan, 22, 30 36 (1981).

4) Nakayama, A., Shinya, R.: ibid., 22, 37 41 (1981).

5) American Public Health Association: "Standard Methods for the Examination of Dairy Products, 14th ed." ed. by Marth, E. H., p. 67 68 (1978), American Public Health Association, New York.

6) Sakazaki, R.: Bacterial Culture Media, Part I, p. 277 278 (1978), Kindai Shuppan, Tokyo.

7) Munakata, N., Rupert, C.S.: J. Bacteriol., 111, 192 198 (1972). 